\title{
Can antibodies with specificity for soluble antigens mimic the therapeutic effects of intravenous IgG in the treatment of autoimmune disease?
}

\author{
Vinayakumar Siragam,,1,2 Davor Brinc, ${ }^{1,2}$ Andrew R. Crow, ${ }^{1,2}$ Seng Song, ${ }^{1}$ \\ John Freedman,1,2,3 and Alan H. Lazarus ${ }^{1,2,3}$
}

\begin{abstract}
${ }^{1}$ Transfusion Medicine Research and the Department of Laboratory Medicine and Pathobiology, St. Michael's Hospital, ${ }^{2}$ The Canadian Blood Services, and ${ }^{3}$ Department of Medicine, University of Toronto and the Toronto Platelet Immunobiology Group, Toronto, Ontario, Canada.
\end{abstract}

\begin{abstract}
Intravenous Ig (IVIg) mediates protection from the effects of immune thrombocytopenic purpura (ITP) as well as numerous other autoimmune states; however, the active antibodies within IVIg are unknown. There is some evidence that antibodies specific for a cell-associated antigen on erythrocytes are responsible, at least in part, for the therapeutic effect of IVIg in ITP. Yet whether an IVIg directed to a soluble antigen can likewise be beneficial in ITP or other autoimmune diseases is also unknown. A murine model of ITP was used to determine the effectiveness of IgG specific to soluble antigens in treating immune thrombocytopenic purpura. Mice experimentally treated with soluble OVA + anti-OVA versus mice treated with OVA conjugated to rbcs (OVArbcs) + anti-OVA were compared. In both situations, mice were protected from ITP. Both these experimental therapeutic regimes acted in a complement-independent fashion and both also blocked reticuloendothelial function. In contrast to OVA-rbcs + anti-OVA, soluble OVA + anti-OVA (as well as IVIg) did not have any effect on thrombocytopenia in mice lacking the inhibitory receptor $\mathrm{Fc} \gamma \mathrm{RIIB}\left(\mathrm{F} \gamma \gamma \mathrm{RIIB} \mathrm{B}^{-/}\right.$mice). Similarly, antibodies reactive with the endogenous soluble antigens albumin and transferrin also ameliorated ITP in an Fc $\gamma$ RIIBdependent manner. Finally, broadening the significance of these experiments was the finding that anti-albumin was protective in a $\mathrm{K} / \mathrm{BxN}$ serum-induced arthritis model. We conclude that IgG antibodies directed to soluble antigens ameliorated 2 disparate IVIg-treatable autoimmune diseases.
\end{abstract}

\section{Introduction}

Immune thrombocytopenic purpura (ITP) is an autoimmune disease characterized by platelet clearance mediated by pathogenic antiplatelet antibodies (1-3). It is thought that this platelet clearance is mediated by $\mathrm{Fc} \gamma$ receptor-bearing ( $\mathrm{F} c \gamma \mathrm{R}$-bearing) macrophages in the reticuloendothelial system (RES) (4). While intravenous Ig (IVIg) is widely used in the treatment of ITP and other autoimmune/inflammatory diseases, its mechanism of action has not been fully elucidated. In murine models of ITP, it has been demonstrated that IVIg ameliorates ITP by a mechanism dependent upon the expression of the inhibitory Fc $\gamma \mathrm{R}$ Fc $\gamma$ RIIB $(5,6)$. In addition, IVIg induces RES blockade $(4,7,8)$; this "competitive" RES blockade has long been considered to be the primary mechanism whereby IVIg increases platelet counts in patients with $\operatorname{ITP}(4,9,10)$. We have previously found that IVIg (11) and some monoclonal mimetics of IVIg (12) can block murine RES function.

IVIg can potentially bind to a number of different cell surface or soluble antigens (13-21), and antibody specificities within IVIg may be responsible for different therapeutic effects through a vari-

Nonstandard abbreviations used: $F c \gamma R$, Fc receptor; FcRn, neonatal Fc receptor; ITP, immune thrombocytopenic purpura; IVIg, intravenous Ig; RES, reticuloendothelial system.

Conflict of interest: The authors have declared that no conflict of interest exists.

Citation for this article: J. Clin. Invest. 115:155-160 (2005).

doi:10.1172/JCI200522753. ety of mechanisms (22-29). We undertook the present study to establish whether antibodies to soluble antigens could ameliorate ITP. In particular, IgGs targeted to either a soluble or a cell-bound antigen were compared in murine ITP. OVA was selected as the primary target antigen because it can be used in its soluble form or can be coupled to syngeneic rbcs (OVA-rbcs), and the same antiOVA antibody can be used with both OVA and OVA-rbcs.

We demonstrate that, like IVIg, antibodies to soluble antigens can ameliorate ITP in an Fc $\gamma$ RIIB- dependent manner. In addition, anti-albumin was protective for $\mathrm{K} / \mathrm{BxN}$ serum-induced inflammatory arthritis $(30,31)$. Taken together, these new data demonstrate that IgG reactive with soluble antigens can mimic the therapeutic effects of IVIg in treating these 2 different autoimmune diseases.

\section{Results}

IgG reactive with a soluble antigen can ameliorate ITP. CD1 mice were injected with $1 \mathrm{mg}$ soluble OVA that had been preincubated with the indicated concentration of anti-OVA (Figure 1, gray bars), IVIg, or nothing 1 day prior to injection of antiplatelet antibody. After an additional 24 hours, all mice were bled for platelet counts. Mice that received anti-platelet antibody alone displayed ITP, compared with control mice (horizontal white bar). The OVA + anti-OVA preparation significantly prevented thrombocytopenia at dosages of 1.0 and $0.5 \mathrm{mg}$ anti-OVA/mouse $(P<0.001)$ as assessed by platelet counts 24 hours after anti-platelet antibody injection. In addition, IVIg (50 mg/mouse) also significantly inhibited the onset of 


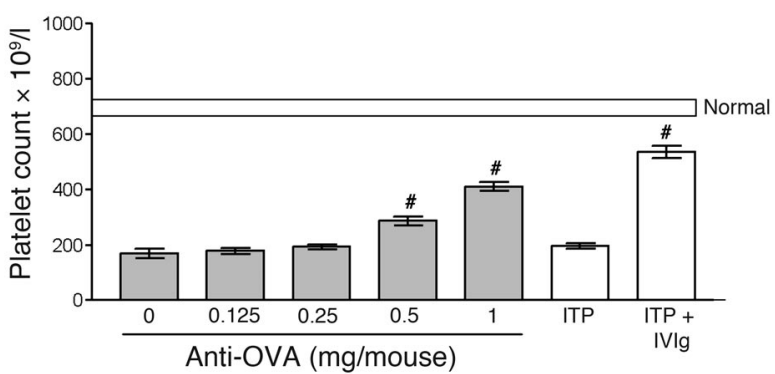

\section{Figure 1}

Pretreatment of mice with soluble OVA + anti-OVA ameliorates ITP. CD1 mice were pretreated by intravenous injection of $1 \mathrm{mg}$ OVA that had been preincubated with the indicated dose of anti-OVA (gray bars), followed 24 hours later by injection of $2 \mu \mathrm{g}$ anti-platelet antibody. The $x$ axis denotes the treatment; $y$ axis denotes platelet counts taken 24 hours after injection with anti-platelet antibody. Normal, unmanipulated mice (the white horizontal bar represents the mean platelet count \pm 1 SEM); ITP, mice injected with antiplatelet antibody only; ITP + IVIg, mice pretreated with $50 \mathrm{mg}$ IVIg followed by antiplatelet antibody; $n=9$ mice for each group from 3 independent experiments. $\# P<0.001$ vs. ITP mice. Data are presented as mean \pm SEM.

ITP. Individually, neither OVA (first column) nor anti-OVA (data not shown) alone affected the platelet count. Mice treated with $\mathrm{OVA}+$ control IgG were also not protected from the development of ITP (data not shown). In addition, we have also observed that a $50 \mu \mathrm{g} /$ mouse dose of monoclonal anti-OVA in combination with 1 $\mathrm{mg}$ of soluble OVA was as successful at ameliorating ITP as was 50 mg IVIg (Supplemental Figure 2; supplemental material available online with this article; doi:10.1172/JCI200522753DS1).

IgG reactive with a cell-associated antigen can ameliorate ITP. CD1 mice were injected intravenously with $10^{8}$ OVA-rbcs, OVA-rbcs + anti-OVA, or OVA-rbcs + control IgG or $50 \mathrm{mg}$ IVIg or were left untreated. Twenty-four hours later, mice received an injection of antiplatelet antibody; after an additional 24 hours, all mice were bled. Mice treated with OVA-rbcs + anti-OVA (Figure 2) were significantly protected from the development of thrombocytopenia $(P<0.001)$ compared with mice receiving OVA-rbcs alone or the other control groups.

IgG reactive with a soluble or cell-associated antigen blocks $R E S$ function. To assess whether the regimes under study inhibited RES function, we analyzed the clearance rate of fluorescently labeled, antibody-sensitized, syngeneic rbcs. For the soluble antigen studies, mice were either untreated or injected with OVA + anti-OVA or OVA + control IgG or IVIg, followed 24 hours later by sensitized, fluorescent rbcs (Figure 3A). IVIg significantly inhibited rbc clearance, as we have previously shown (11). Mice pretreated with OVA + anti-OVA had a significantly impaired ability to clear sensitized rbcs $(P<0.001$ at 30,120 and 1,000 min). Mice pretreated with OVA + control IgG displayed the same clearance rate as otherwise untreated mice. For the cell-associated antigen studies, mice were untreated or injected with OVA-rbcs + anti-OVA or OVA-rbcs + control IgG or IVIg (Figure 3B). Mice pretreated with OVA-rbcs + anti-OVA had a significantly impaired ability to clear sensitized $\operatorname{rbcs}(P<0.01$ at $10 \mathrm{~min} ; P<0.001$ at 30,120 and 1,000 min) as compared with otherwise untreated mice.

$F C \gamma R I I B$ expression is required for protection with soluble but not cellassociated antigens. C57BL/6 $\left(F_{C \gamma} R_{I I} B^{+/+}\right)$mice and $F_{C \gamma} R I I B^{-/-}$mice were injected daily with antiplatelet antibody to induce stable thrombocytopenia. Mice were then treated with OVA + anti-OVA or OVA + control IgG or IVIg 2 days after ITP induction. Treatment of mice with OVA + anti-OVA or IVIg significantly reversed ITP in wild-type mice ( $P<0.001$ at days 3 and 4 ) (Figure 4A). However, we found that neither OVA + anti-OVA nor IVIg ameliorated ITP in $F c \gamma R I I B^{-/-}$mice (Figure 4B).

In sharp contrast to the results with the soluble OVA antigen system, both wild-type (Figure 5A) and FcyRIIB ${ }^{-/-}$mice (Figure 5B) showed significant increases in platelet counts after treatment with OVA-rbcs + anti-OVA ( $P<0.001$ at days 3 and 4). Although the genetic backgrounds of the $F_{C \gamma} R_{I I B}{ }^{-/-}$mice and the $F_{c \gamma} R I I B^{+/+}$ mice are not identical, these data confirm earlier observations that Fc $\gamma$ RIIB is required for IVIg action (5).

IgG reactive with preinjected or endogenous antigens can ameliorate ITP. To determine whether it is necessary to incubate antigen and antibody before injection to ameliorate the thrombocytopenia in our model, we preinjected mice with either $1 \mathrm{mg}$ or $10 \mathrm{mg}$ OVA followed by $1 \mathrm{mg}$ anti-OVA after 4 hours. Significant reversal of ITP was achieved with anti-OVA in these mice (Figure 6A). To ascertain whether antibody to endogenous soluble antigens could also ameliorate ITP, thrombocytopenic mice were treated with 1 $\mathrm{mg}$ anti-albumin or $1 \mathrm{mg}$ anti-transferrin on day 2 (Figure $6 \mathrm{~B}$ ). Anti-albumin significantly increased platelet counts of thrombocytopenic mice at days $3(P<0.01)$ and $4(P<0.001)$. Anti-transferrin also increased platelet counts at days 3 and $4(P<0.01$ at day 4). IVIg, but not control IgG, successfully increased platelet counts at days 3 and 4 .

IgG reactive with a soluble antigen can ameliorate inflammatory arthritis. To evaluate the therapeutic role of antibodies directed to a soluble antigen in the $\mathrm{K} / \mathrm{BxN}$ serum-induced arthritis model, we injected C57BL/6 mice with $50 \mathrm{mg}$ IVIg, $1 \mathrm{mg}$ antialbumin, $1 \mathrm{mg}$ control IgG, or nothing 4 hours prior to administering $\mathrm{K} / \mathrm{BxN}$ serum. Mice in an additional control group were not injected with the $\mathrm{K} / \mathrm{BxN}$ serum. Mice that received $\mathrm{K} / \mathrm{BxN}$ serum alone, or $\mathrm{K} / \mathrm{BxN}$ serum + control IgG, developed joint swelling, which reached a plateau by day 8 after injection (Figure 7, A and B). IVIg and the anti-albumin treatment significantly ameliorated the arthritis as assessed by ankle width measurements as well as by clinical score, as compared with mice that received $\mathrm{K} / \mathrm{BxN}$ serum or $\mathrm{K} / \mathrm{BxN}$ serum plus treatment with control IgG (Figure 7, A and B).

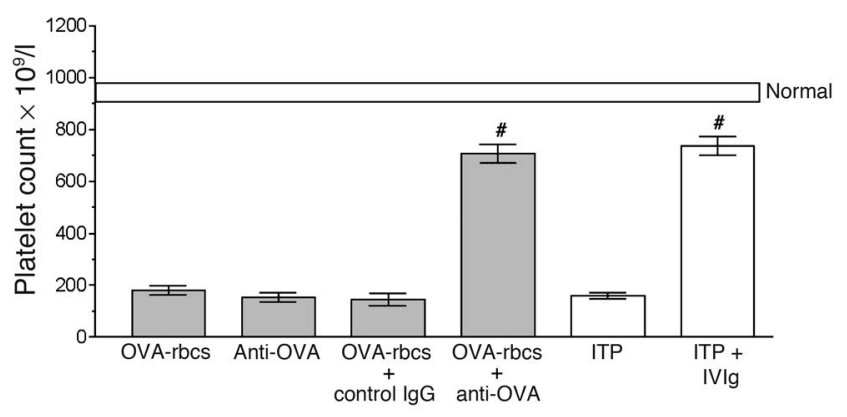

Figure 2

Pretreatment of mice with OVA-rbcs + anti-OVA ameliorates ITP. CD1 mice were injected intravenously with $10^{8}$ OVA-rbcs + anti-OVA or OVA-rbcs + control IgG, or OVA-rbcs or anti-OVA only, as indicated on the $x$ axis. Mice were then treated as described in Figure 1. $n=9$ mice for each group from 3 independent experiments. $\# P<0.001$ vs. ITP mice. Data are presented as mean \pm SEM. 

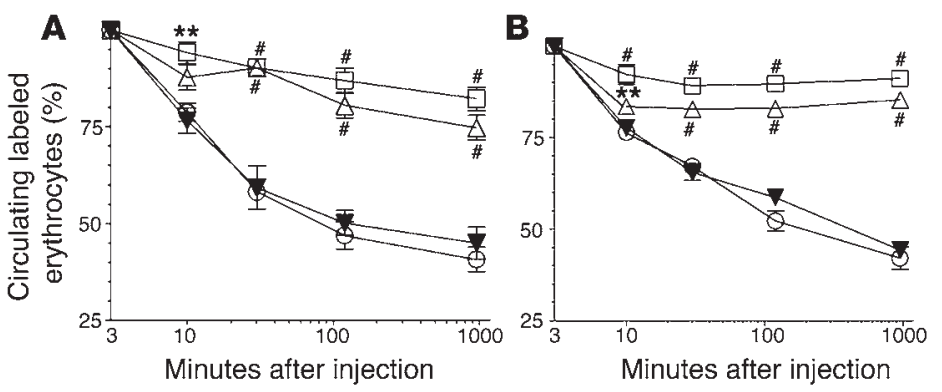

Figure 3

Antibody reactive with soluble OVA or OVA-rbcs inhibits RES function. (A) RES blockade using soluble OVA. CD1 mice were untreated (open circles), treated intraperitoneally with IVIg (open squares), or intravenously with OVA + anti-OVA (open triangles) or OVA + control IgG (filled triangles), followed 24 hours later by intravenous injection of fluorescently labeled, TER-119-opsonized syngeneic rbcs. Blood samples were taken at the times indicated on the $x$ axis and the percentage of fluorescent rbcs in the circulation assessed by flow cytometry. (B) RES blockade using OVA-rbcs. Mice were not pretreated (open circles), pretreated intraperitoneally with $50 \mathrm{mg} I \mathrm{VIg}$ (open squares), or pretreated intravenously with $10^{8}$ OVA-rbcs sensitized with 10 $\mu \mathrm{g}$ anti-OVA (open triangles) or OVA-rbcs pretreated with control IgG (filled triangles), followed 24 hours later by intravenous injection of fluorescently labeled TER-119-opsonized syngeneic rbcs. The percentage of fluorescent rbcs was assessed as in $\mathbf{A}$. The percentage of fluorescent rbcs at 3 min was considered to be $100 \% ; n=5$ mice for each group from 5 independent experiments. ${ }^{* \star} P<0.01,{ }^{\#} P<0.001$. Data are presented as mean \pm SEM.

\section{Discussion}

We evaluated the ability of antibodies that target soluble antigens to ameliorate ITP and compared the mechanism of action of this therapeutic strategy to that of antibodies directed to a cell-associated antigen. OVA was used as the primary model antigen because it is absent in mice and can be prepared in either a soluble or cellassociated form (32), which allowed us to test the same anti-OVA antibody with both soluble and cell-associated OVA.

IVIg has been shown to require the presence of the inhibitory FcyRIIB to ameliorate murine ITP $(5,6)$. In wild-type mice, antibodies to both soluble and cell-associated OVA ameliorated ITP to the same extent as did IVIg. In Fc $R^{R I I B^{-/-}}$mice, however, targeting soluble OVA did not ameliorate ITP. In contrast, targeting cell-associated OVA ameliorated ITP in Fcy RIIB ${ }^{-/-}$mice. The findings suggest that antibodies to soluble antigens function via a mechanism similar to that of IVIg, whereas antibodies reactive to cell-associated antigens function by a different pathway. The observation that OVA-rbcs + anti-OVA is effective in the absence of FcyRIIB suggests that it may function by inhibiting activating FCy receptors on macrophages in the RES. All of the 3 therapeu- tic regimes that resolved ITP (soluble, particulate, IVIg) also blocked the ability of the RES to clear antibody-sensitized fluorescently labeled erythrocytes. RES blockade has long been considered to be a primary mechanism of action of both IVIg and a different IgG therapeutic product (anti-RhD) in the treatment of ITP $(4,7-10,33)$. While our work does not directly examine the mechanism that each of these therapeutic regimes could use to inhibit RES function, the observation that IVIg and antibodies to soluble antigens (but not to OVA-rbcs) resolve ITP in an Fc $\gamma$ RIIB-dependent manner argues that this mechanism may be more complex than originally thought. In particular, RES inhibition may occur via several distinct mechanisms, including (a) competition for activating FcyRs; (b) macrophage exhaustion (by engulfment and antigen processing of sensitized erythrocytes); or (c) inhibitory signaling via Fc $\gamma$ RIIB (in the case of IVIg and/or antibodies to soluble antigens). The precise details of how each of these regimes inhibits the function of the RES remain to be determined, although blockade of the RES by antibodies to particulate antigens (i.e., that ameliorate ITP independent of Fc $\gamma$ RIIB) suggests it may function by either of the first 2 mechanisms (a or b). In the case of antibodies to soluble antigens, we have observed that they ameliorated both murine ITP as well as inflammatory arthritis. Since the immunological mechanisms involved in both of these diseases are different with respect to the involvement of a functioning RES (i.e., phagocytosis of opsonized platelets in the spleen vs. inflammation and joint destruction), we do not believe that simple RES competitive blockade fully explains the therapeutic effects of anti-soluble antigen-mediated amelioration of autoimmune-disease.

In this study, mice were injected with OVA (or OVA-rbcs) that had been pretreated with anti-OVA in vitro, followed by the in vivo administration of this antibody-antigen mixture. Although this exogenous antigen strategy worked well in our model, it might not be feasible in humans with ITP. To determine whether IgG reactive with soluble endogenous antigens also could increase platelet counts in thrombocytopenic mice, mice were injected with anti-albumin or anti-transferrin. Both of these antibodies also ameliorated the ITP in control mice but were not successful at ameliorating ITP in $\mathrm{Fc \gamma RIIB}^{-/-}$mice as expected (Supplemental Figure 3), indicating that, similarly to OVA + anti-OVA, IgG reactive with endogenous soluble antigens also functions in an IVIg-like manner.

It has also been suggested that IVIg mediates its effect in inflammatory disease by affecting complement activation (34-38). We found that the therapeutic effect of all of the preparations tested

\section{Figure 4}

Fc $\gamma$ RIIB expression is required for reversal of ITP by soluble

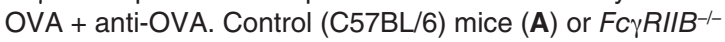
mice $(\mathbf{B})$ were injected with $2 \mu \mathrm{g}$ anti-platelet antibody on days 0 through 3 (upward-pointing arrows). On day 2 (downward-pointing arrows) mice were injected intraperitoneally with IVIg (open squares) or intravenously with OVA + antiOVA (open triangles) or OVA + control lgG (filled triangles). Mice were bled daily for platelet counting; $n=5$ mice for each group from 5 independent experiments. ${ }^{\#} P<0.001$ vs. control IgG. Data are presented as mean \pm SEM.

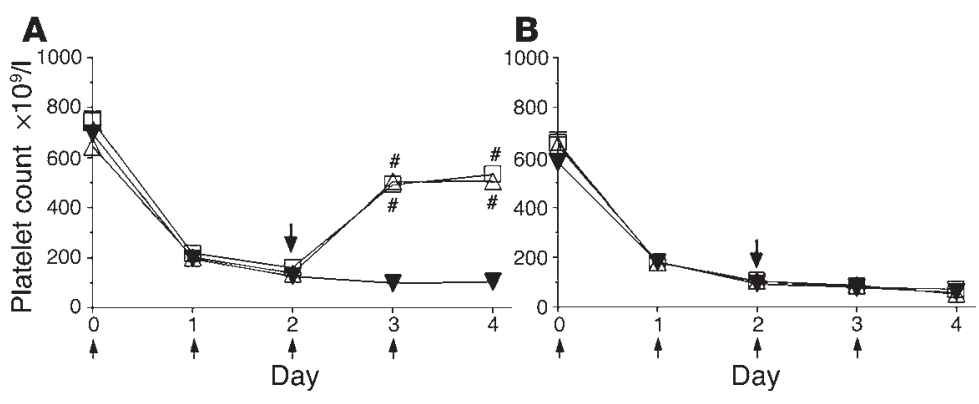



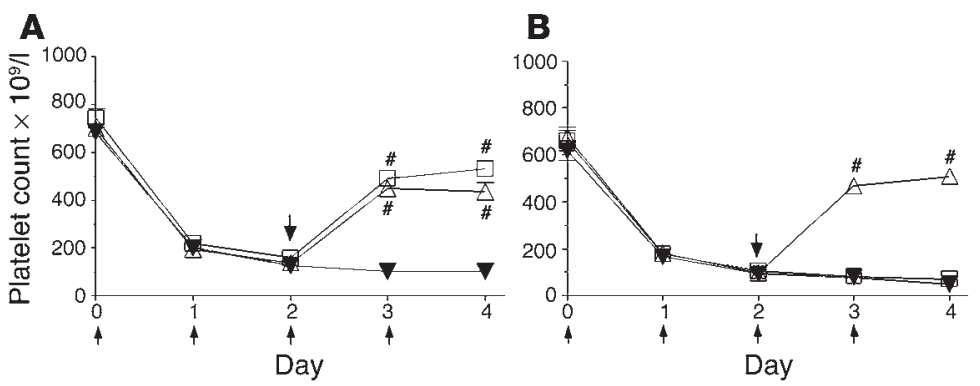

Figure 5

FcyRIIB expression is not required for reversal of ITP by OVA-rbcs + anti-OVA. Control (C57BL/6) mice (A) or FCyRIIB-/- mice (B) were injected with $2 \mu \mathrm{g}$ antiplatelet antibody on days 0 through 3 (upward-pointing arrows). On day 2 (downward-pointing arrows) mice were injected intraperitoneally with $50 \mathrm{mg} I \mathrm{VIg}$ (open squares) or intravenously with OVA-rbcs + anti-OVA (open triangles) or OVA-rbcs + control IgG (filled triangles). Platelet counting was as described in Figure 4; $n=5$ mice for each group from 5 independent experiments. ${ }^{*} P<0.001$ vs. OVArbcs alone. Data are presented as mean \pm SEM.

was, however, similar in normal mice and mice depleted of complement by cobra venom factor (Supplemental Figure 4). In addition, the fact that the monoclonal antibody directed to OVA was successful in ameliorating ITP under the conditions used (OVA was incubated with the monoclonal anti-OVA antibody at approximately 67:1 molar ratio; see Supplemental Figure 2) makes it unlikely that antibodies reactive with soluble antigens must form large immune complexes that activate complement as part of their therapeutic effectiveness. This is consistent with the work of Samuelsson et al., who observed that IVIg can inhibit ITP in mice genetically deficient in C3 (5).

A recent report by Akilesh and coworkers has demonstrated that the neonatal $\mathrm{Fc}$ receptor $(\mathrm{FcRn})$ may have a role in the antiinflammatory action of IVIg in the $\mathrm{K} / \mathrm{BxN}$ serum-induced arthritis model (39). Work by this group and others suggests that IVIg occupies the FcRn, displacing the binding of the pathogenic antibodies, which leads to an increased catabolism of IgG. Since albumin can also bind to the FcRn, which prolongs its lifespan (40), a similar mechanism could be proposed for explaining the effects of the anti-albumin and perhaps the anti-OVA (+ OVA) in both the ITP and the $\mathrm{K} / \mathrm{BxN}$ serum-induced arthritis models. One possibility is that the combination of IgG + albumin might more effectively compete for the IgG binding sites of FcRn, thus diverting higher levels of the pathogenic antibodies to degradation. The only caveat with this concept is that the fractional catabolic rate of transferrin does not appear to be directly related to its serum concentration, and, therefore, transferrin may not meaningfully interact with the FcRn $(41,42)$. Since anti-transferrin antibody ameliorated murine ITP almost as well as anti-albumin did, this last observation does not support this theory.

In conclusion, we demonstrate that antibodies to an otherwise immunologically inert soluble antigen can ameliorate both ITP and inflammatory arthritis. These observations suggest that antibodies to human proteins, such as albumin or transferrin, for example, could potentially augment or perhaps even replace current therapies such as IVIg in the treatment of some autoimmune diseases.

\section{Methods}

Mice. CD1 mice (6-10 wk of age) were purchased from Charles River Laboratories Inc. C57BL/6 and $\mathrm{Fc}_{\mathrm{N}} \mathrm{RIIB}^{-/-}$(B6;129S4$\left.\mathrm{Fc} \gamma \mathrm{r} 2 \mathrm{~b}^{\mathrm{tm} 1 \mathrm{Rav}} / \mathrm{J}\right)$ mice were purchased from The Jackson Laboratory. All mice were housed in the St. Michael's Hospital Research Vivarium. All methods involving animals in this study have been approved by the Animal Care Committee of St. Michael's Hospital, Toronto, Ontario, Canada.

Reagents. The monoclonal antibody specific for integrin $\alpha_{\mathrm{IIb}}\left(\right.$ rat $\mathrm{IgG}_{1 \kappa}$, clone MWReg 30) was purchased from BD Biosciences - Pharmingen. OVA (grade V), rabbit IgG anti-OVA, 1-ethyl-3-(3-dimethylamino-propyl) carbodiimide (EDAC), and PKH26 Red Fluorescent Cell Linker Kit were purchased from Sigma-Aldrich. The IVIg (Gamimune N, 10\%) was from Bayer Inc. FITC-conjugated $\mathrm{F}\left(\mathrm{ab}^{\prime}\right)_{2}$ anti-rabbit IgG and control (rabbit) IgG were purchased from Cedarlane Laboratories Ltd. Rabbit IgG anti-albumin and anti-transferrin were purchased from Research Diagnostics Inc. The monoclonal antibody anti-TER119 specific for murine erythrocytes (clone TER-119, rat IgG Ig $_{2 b}$ ) was purchased from BD Biosciences - Pharmingen. Microdispenser tubes $(250 \mu \mathrm{l})$ for blood collection were from VWR International. Soluble and particulate antigen studies. OVA + anti-OVA: One milligram OVA was dissolved in PBS and was incubated with $1 \mathrm{mg}$ anti-OVA (unless otherwise indicated) for 1 hour at $37^{\circ} \mathrm{C}$. The solution was then injected intravenously in a 200- $\mu \mathrm{l}$ volume. Control groups included mice treated with OVA only, anti-OVA only, or OVA preincubated with control IgG.

OVA-rbcs + anti-OVA: OVA was coupled to rbcs by a modified version of that employed by Soldera et al. (32). Then rbcs were resuspended at $2.5 \times 10^{8} / \mathrm{ml}$ in $5 \mathrm{mg} / \mathrm{ml}$ OVA in saline, and $1.9 \mathrm{mg} / \mathrm{ml} \mathrm{EDAC}$ was added. After a 1-hour incubation at $4{ }^{\circ} \mathrm{C}$, the cells were washed once with a $2 \mathrm{mg} / \mathrm{ml}$ solution of OVA in PBS followed by 1 wash in PBS. The presence of OVA on rbcs was established by flow cytometry (Supplemental Figure 1). For treatment of ITP, $10^{8}$ OVA-rbcs were sensitized with $10 \mu \mathrm{g}$ of antiOVA for 1 hour at $22^{\circ} \mathrm{C}$ and injected intravenously in a volume of $200 \mu \mathrm{l}$. Control IgG was used as a control.

Induction and treatment of ITP. Mice were rendered thrombocytopenic by intraperitoneal injection of $2 \mu \mathrm{g}$ anti-integrin $\alpha_{\mathrm{IIb}}$ antibody in $200 \mu \mathrm{l} \mathrm{PBS}$, $\mathrm{pH} 7.2$, as previously described $(11,12)$. For experiments where the experimental therapeutic intervention preceded the induction of ITP (as shown,

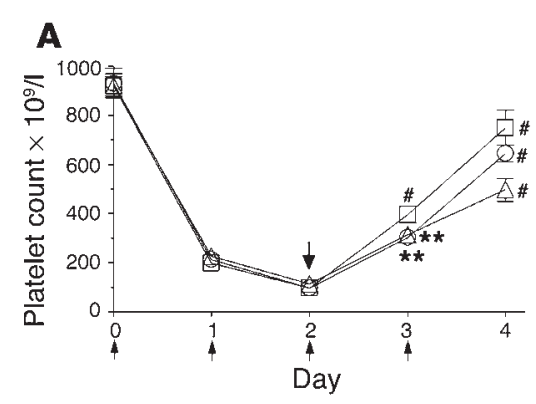

Figure 6

Antibodies to endogenous soluble antigens ameliorate ITP. Thrombocytopenia was induced and platelets counted as described in Figure 4. On day 2 (downwardpointing arrow), CD1 mice were treated (A) intraperitoneally with 50 mg IVIg only (open squares), $1 \mathrm{mg}$ OVA (open circles), or $10 \mathrm{mg}$ OVA (open triangles), followed 4 hours later by $1 \mathrm{mg}$ anti-OVA intravenously; (B) intraperitoneally with $50 \mathrm{mg}$ IVIg (open squares) or intravenously with $1 \mathrm{mg}$ anti-albumin antibody (filled triangles), $1 \mathrm{mg}$ anti-transferrin antibody (open circles), or $1 \mathrm{mg}$ control IgG (filled diamonds); $n=6$ mice for each group from 2 independent experiments. ${ }^{\sharp} P<0.001,{ }^{\star \star} P<0.01$, treatment vs. control IgG. Data are presented as mean \pm SEM. 

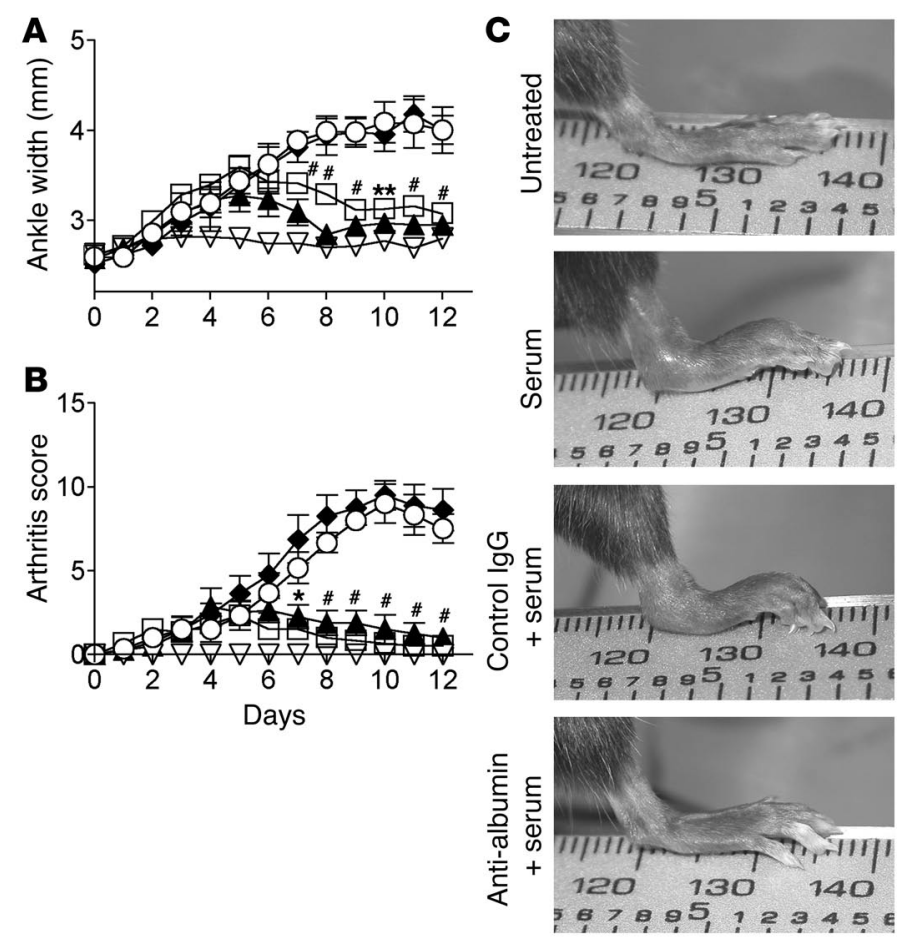

\section{Figure 7}

Antibodies to murine albumin ameliorate $\mathrm{K} / \mathrm{BxN}$ serum-induced inflammatory arthritis. (A) Ankle width and (B) overall arthritis score following induction of arthritis by injection with $\mathrm{K} / \mathrm{BxN}$ serum. $\mathrm{C} 57 \mathrm{BL} / 6$ mice were injected on day 0 with $\mathrm{K} / \mathrm{BxN}$ serum (open circles), IVIg $+\mathrm{K} / \mathrm{B} \times \mathrm{N}$ serum (open squares), anti-albumin $+\mathrm{K} / \mathrm{BxN}$ serum (filled triangles), or control IgG $+\mathrm{K} / \mathrm{BxN}$ serum (filled diamonds) or left untreated (open triangles). ${ }^{\#} P<0.001,{ }^{\star *} P<0.01$, ${ }^{*} P<0.05$, anti-albumin vs. control IgG. Data represented as the mean \pm SEM; $n=3$ from 2 independent experiments (with serum and with IVIg + serum); $n=4$ from 3 independent experiments (untreated and treated with control IgG + serum and anti-albumin + serum). (C) Hind limbs of representative C57BL/6 mice at day 9 after serum injection. for example, in Figures 1 and 2), mice were first injected intravenously with OVA + anti-OVA or OVA-rbcs + anti-OVA followed at 24 hours by a single injection of antiplatelet antibody. Mice were bled for platelet counts after an additional 24 hours. For experiments where ITP preceded the therapeutic intervention (as shown, for example, in Figures 4-6), mice were injected daily with anti-platelet antibody and then with the test preparation on day 2. Mice were bled daily and platelets counted as described below.

In experiments where we wished to avoid the possibility of the formation of "pre-formed" immune complexes, mice were injected intraperitoneally with the indicated dose of soluble OVA and 4 hours later by $1 \mathrm{mg}$ anti-OVA in a volume of $200 \mu \mathrm{l}$ intravenously. Mice injected with anti-albumin or anti-transferrin alone received $1 \mathrm{mg}$ of antibody intravenously in $200 \mu \mathrm{l}$ PBS, pH 7.2, on day 2 .

For all IVIg treatments, mice were injected intraperitoneally with $50 \mathrm{mg}$ of IVIg (equivalent to $2 \mathrm{~g} / \mathrm{kg}$ body weight). Platelets were counted as previously described $(6,11,12)$, with the following minor modifications. Mouse blood $(45 \mu \mathrm{l})$ was collected via bleeding from the saphenous vein into microdispenser tubes preloaded with $5 \mu \mathrm{l}$ of $1 \%$ EDTA in PBS and then further diluted to a final dilution of 1:12,000 in 1\% EDTA/PBS. Platelets were counted on a flow rate-calibrated FACScan Flow Cytometer (BD). Forward scatter versus side scatter was used to gate platelets as previously described $(11,12)$.

RES blockade. RES blockade was assessed as previously described (12). Briefly, rbcs were opsonized with $8 \mu \mathrm{g}$ of anti-TER-119 antibody at $22^{\circ} \mathrm{C}$ for 30 minutes. The opsonized rbcs were then labeled with the PKH26 fluorescent marker according to the manufacturer's directions. These clear antibody-sensitized fluorescently labeled cells in a volume of $200 \mu \mathrm{l}$ were injected into the mice via the tail vein. At the indicated times after injection of these rbcs, mice were bled, and the percentage of fluorescent rbcs remaining in circulation was ascertained by flow cytometry as described (12).

$K / B x N$ serum-induced arthritis and arthritis scoring. For induction of arthritis, mice were given a single intraperitoneal injection of $600 \mu \mathrm{l}$ of diluted serum (diluted to $50 \%$ strength with PBS), as described by Akilesh et al. (39). Mice in an additional control group were left untreated. Ankle width was measured laterally across the joint with a caliper (39). Arthritis was also clinically scored daily by an independent observer blinded to the treatment of the mice. Each paw was scored as follows: 0, unaffected; 1, slight swelling; 2, moderate swelling; 3 , severe swelling involving the entire paw (foot, digits, ankle); and the overall score was calculated as the sum of individual scores for each paw as described by de Fougerolles et al. (43). Mice injected with anti-albumin or the IgG control received $1 \mathrm{mg}$ of IgG intravenously in $200 \mu \mathrm{l}$ PBS 4 hours prior to the induction of arthritis. Mice in the IVIg group were injected intraperitoneally with $50 \mathrm{mg}$ of IVIg 4 hours prior to the induction of arthritis.

Statistical analysis. Data was analyzed using the Student's $t$ test or by 1-way ANOVA, as appropriate. $P<0.05$ was considered significant.

\section{Acknowledgments}

We wish to thank Derry Roopenian for generously providing $\mathrm{K} / \mathrm{BxN}$ serum. We thank Hoang Le-Tien, Alison F. Starkey, and Zoë Cohen for assistance and helpful discussion; John W. Semple and Paul Doherty for critical review of the manuscript; and St. Michael's Hospital Research Vivarium staff. This work was supported by a grant from the Canadian Blood Services-Canadian Institutes of Health Research Request for Proposals Program Fund. Vinayakumar Siragam was the recipient of a Post Doctoral Fellowship from the Canadian Blood Services. Davor Brinc was supported by a Graduate Fellowship from the Canadian Blood Services.

Received for publication July 19, 2004, and accepted in revised form November 2, 2004.

Address correspondence to: Alan H. Lazarus, Transfusion Medicine Research, St. Michael's Hospital, 30 Bond Street, Toronto, Ontario M5B 1W8, Canada. Phone: (416) 864-5599; Fax: (416) 864-3021; E-mail: lazarusa@smh.toronto.on.ca.

Vinayakumar Siragam and Davor Brinc contributed equally to this work. 
1. McMillan, R., Longmire, R.L., Yelenosky, R., Donnell, R.L., and Armstrong, S. 1974. Quantitation of platelet-binding IgG produced in vitro by spleens from patients with idiopathic thrombocytopenic purpura. N. Engl. J. Med. 291:812-817.

2. Saleh, M.N., Moore, D.L., Lee, J.Y., and LoBuglio, A.F. 1989. Monocyte-platelet interaction in immune and nonimmune thrombocytopenia. Blood. 74:1328-1331.

3. Semple, J.W. 2002. Immune pathophysiology of autoimmune thrombocytopenic purpura. Blood Rev. 16:9-12.

4. Bussel,J.B. 2000. Fc receptor blockade and immune thrombocytopenic purpura. Semin. Hematol. 37:261-266.

5. Samuelsson, A., Towers, T.L., and Ravetch, J.V. 2001. Anti-inflammatory activity of IVIG mediated through the inhibitory Fc receptor. Science. 291:484-486.

6. Crow, A.R., et al. 2003. IVIg-mediated amelioration of murine ITP via Fc $\gamma$ RIIB is independent of SHIP1, SHP-1, and Btk activity. Blood. 102:558-560.

7. Fehr, J., Hofmann, V., and Kappeler, U. 1982. Transient reversal of thrombocytopenia in idiopathic thrombocytopenic purpura by high-dose intravenous gamma globulin. N. Engl. J. Med. 306:1254-1258.

8. Salama, A., Mueller-Eckhardt, C., and Kiefel, V. 1983. Effect of intravenous immunoglobulin in immune thrombocytopenia. Lancet. 2:193-195

9. Salama, A., Kiefel, V., Amberg, R., and Mueller-Eckhardt, C. 1984. Treatment of autoimmune thrombocytopenic purpura with rhesus antibodies (antiRh0(D)]. Blut. 49:29-35.

10. Lazarus, A.H., and Crow, A.R. 2003. Mechanism of action of IVIG and anti-D in ITP. Transfus. Apheresis Sci. 28:249-255.

11. Crow, A.R., Song, S., Semple, J.W., Freedman, J., and Lazarus, A.H. 2001. IVIg inhibits reticuloendothelial system function and ameliorates murine passiveimmune thrombocytopenia independent of antiidiotype reactivity. Br. J. Haematol. 115:679-686.

12. Song, S., Crow, A.R., Freedman, J., and Lazarus, A.H. 2003. Monoclonal IgG can ameliorate immune thrombocytopenia in a murine model of ITP: an alternative to IVIG. Blood. 101:3708-3713.

13. Rossi, F., Dietrich, G., and Kazatchkine, M.D. 1989. Anti-idiotypes against autoantibodies in normal immunoglobulins: evidence for network regulation of human autoimmune responses. Immunol. Rev. 110:135-149.

14. Marchalonis, J.J., et al. 1992. Human autoantibodies reactive with synthetic autoantigens from T-cell receptor beta chain. Proc. Natl. Acad. Sci. U. S. A. 89:3325-3329.

15. Vassilev, T., et al. 1993. Antibodies to the CD5 molecule in normal human immunoglobulins for therapeutic use (intravenous immunoglobulins, IVIg). Clin. Exp. Immunol. 92:369-372.

16. Hurez, V., et al. 1994. Anti-CD4 activity of normal human immunoglobulin $\mathrm{G}$ for therapeutic use. (Intravenous immunoglobulin, IVIg). Ther. Immunol. 1:269-277.

17. Svenson, M., et al. 1998. Antibody to granulocytemacrophage colony-stimulating factor is a dominant anti-cytokine activity in human IgG preparations. Blood. 91:2054-2061.

18. Kaveri, S., et al. 1996. Antibodies to a conserved region of HLA class I molecules, capable of modulating CD8 T cell-mediated function, are present in pooled normal immunoglobulin for therapeutic use. J. Clin. Invest. 97:865-869.

19. Viard, I., et al. 1998. Inhibition of toxic epidermal necrolysis by blockade of CD95 with human intravenous immunoglobulin. Science. 282:490-493.

20. Lamoureux, J., Aubin, E., and Lemieux, R. 2003. Autoimmune complexes in human serum in presence of therapeutic amounts of intravenous immunoglobulins. Blood. 101:1660-1662.

21. Lamoureux, J., Aubin, E., and Lemieux, R. 2004. Autoantibodies purified from therapeutic preparations of intravenous immunoglobulins (IVIg) induce the formation of autoimmune complexes in normal human serum: a role in the in vivo mechanisms of action of IVIg? Int. Immunol. 16:929-936.

22. Teeling, J.L., et al. 2001. Therapeutic efficacy of intravenous immunoglobulin preparations depends on the immunoglobulin $\mathrm{G}$ dimers: studies in experimental immune thrombocytopenia. Blood. 98:1095-1099.

23. Zhuang, Q., and Mazer, B. 2001. Inhibition of IgE production in vitro by intact and fragmented intravenous immunoglobulin. J. Allergy Clin. Immunol. 108:229-234

24. Jerzak, M., Rechberger, T., and Gorski, A. 2000. Intravenous immunoglobulin therapy influences $\mathrm{T}$ cell adhesion to extracellular matrix in women with a history of recurrent spontaneous abortions. Am. J. Reprod. Immunol. 44:336-341.

25. Takei, S., Arora, Y.K., and Walker, S.M. 1993. Intravenous immunoglobulin contains specific antibodies inhibitory to activation of $\mathrm{T}$ cells by staphylococcal toxin superantigens. J. Clin. Invest. 91:602-607.

26. Rossi, F., and Kazatchkine, M.D. 1989. Antiidiotypes against autoantibodies in pooled normal human polyspecific Ig. J. Immunol. 143:4104-4109.

27. Abe, Y., Horiuchi, A., Miyake, M., and Kimura, S. 1994. Anti-cytokine nature of natural human immunoglobulin: one possible mechanism of the clinical effect of intravenous immunoglobulin therapy. Immunol. Rev. 139:5-19.

28. Andersson, J.P., and Andersson, U.G. 1990. Human intravenous immunoglobulin modulates mono- kine production in vitro. Immunology. 71:372-376. 29. Ling, Z.D., Ziltener, H.J., Webb, B.T., and Matheson, D.S. 1990. Aggregated immunoglobulin and $\mathrm{Fc}$ fragment of IgG induce IL-6 release from human monocytes. Cell Immunol. 129:95-103.

30. Korganow, A.S., et al. 1999. From systemic T cell self-reactivity to organ-specific autoimmune disease via immunoglobulins. Immunity. 10:451-461.

31. Kouskoff, V., et al. 1996. Organ-specific disease provoked by systemic autoimmunity. Cell. 87:811-822.

32. Soldera, S., McSorley, S.J., and Glaichenhaus, N. 1997. Selective down-regulation of Th2 immune responses following treatment with antigen-coupled splenocytes. Eur. J. Immunol. 27:848-854.

33. Coopamah, M.D., Freedman, J., and Semple, J.W. 2003. Anti-D initially stimulates an Fc-dependent leukocyte oxidative burst and subsequently suppresses erythrophagocytosis via interleukin-1 receptor antagonist. Blood. 102:2862-2867.

34. Mollnes, T.E., et al. 1998. High-dose intravenous immunoglobulin treatment activates complement in vivo. Scand. J. Immunol. 48:312-317.

35. Mollnes, T.E., et al. 1995. Inhibition of complement-mediated red cell lysis by immunoglobulins is dependent on the IG isotype and its C1 binding properties. Scand. J. Immunol. 41:449-456.

36. Basta, M., Kirshbom, P., Frank, M.M., and Fries, L.F. 1989. Mechanism of therapeutic effect of highdose intravenous immunoglobulin. Attenuation of acute, complement-dependent immune damage in a guinea pig model. J. Clin. Invest. 84:1974-1981.

37. Basta, M., Langlois, P.F., Marques, M., Frank, M.M., and Fries, L.F. 1989. High-dose intravenous immunoglobulin modifies complement-mediated in vivo clearance. Blood. 74:326-333.

38. Basta, M. 1996. Modulation of complement-mediated immune damage by intravenous immune globulin. Clin. Exp. Immunol. 104(Suppl. 1):21-25.

39. Akilesh, S., et al. 2004. The MHC class I-like FC receptor promotes humorally mediated autoimmune disease. J. Clin. Invest. 113:1328-1333. doi:10.1172/JCI200418838.

40. Chaudhury, C., et al. 2003. The major histocompatibility complex-related $\mathrm{Fc}$ receptor for $\mathrm{IgG}(\mathrm{FcRn})$ binds albumin and prolongs its lifespan. J. Exp. Med. 197:315-322.

41. Waldmann, T.A., and Strober, W. 1969. Metabolism of immunoglobulins. Prog. Allergy. 13:1-110.

42. Schultze, H.E., and Heremans, J.F. 1966. Molecular biology of human proteins: with special reference to plasma proteins. In Nature and metabolism of extracellular proteins. Elsevier. New York, New York, USA. 904 pp.

43. de Fougerolles, A.R., et al. 2000. Regulation of inflammation by collagen-binding integrins $\alpha 1 \beta 1$ and $\alpha 2 \beta 1$ in models of hypersensitivity and arthritis. J. Clin. Invest. 105:721-729. 